\title{
Ultrastructural changes in the rectal mucosa of patients with rheumatoid arthritis
}

\author{
G R STRUTHERS, C A HOLLYWELL, C J MORRIS, K W WALTON, \\ AND P A BACON \\ From the Department of Rheumatology and Investigative Pathology, Medical School, University of \\ Birmingham, Edgbaston, Birmingham B15 2TJ
}

SUMMARY The rectal mucosa from patients with severe rheumatoid arthritis has been examined by electron microscopy. Initially the patients were biopsied for investigation into the diagnosis of amyloidosis or vasculitis, which proved to be negative. A range of ultrastructural abnormalities was found which included proliferation of the rough endoplasmic reticulum, mitochondrial inclusions, association of the mitochondria with cytoplasmic filaments, and marked increase in the number of iron containing siderosomes. Most of these abnormalities have already been reported in rheumatoid synovial tissue, and attention is drawn to the similarity in findings between these two sites.

Rheumatoid arthritis is now generally accepted to be a systemic disease. ${ }^{1}$ Nonetheless in many patients the only clinical manifestations may be seen in the joints with the appropriate well defined serological parameters. When overt systemic disease occurs it may involve many of the organs of the body producing characteristic symptom complexes. ${ }^{2}$ This systemic involvement is associated with a worse prognosis than the rheumatoid polyarthropathy alone. $^{3-5}$ In certain instances, such as rheumatoid vasculitis, this may be an indication for treatment with stronger agents (steroids and cyclophosphamide). These may have an effect both on the immediate manifestations of the condition, for instance mononeuritis multiplex, and on the long term mortality. ${ }^{6}$

Although on a clinical level we may easily identify those patients who have developed or are developing systemic disease, our knowledge of predisposing factors and pathogenetic mechanisms is more scanty. Both seropositivity and possession of the HLA antigen DRw4 are known to indicate those more likely to develop 'classical' disease. ${ }^{78}$ How these factors influence the underlying cellular and ultrastructural changes is still mainly conjecture.

In this paper we describe marked ultrastructural changes found in the rectal mucosa of patients with rheumatoid arthritis who have a wide variety of

Accepted for publication 8 March 1985.

Correspondence to Dr G R Struthers. extra-articular manifestations and were being investigated for two systemic manifestations vasculitis and amyloidosis. These changes suggest that there are profound intracellular events taking place throughout the body of patients who encompass the whole spectrum of rheumatoid arthritis.

\section{Patients and methods}

\section{CLINICAL}

Deep rectal biopsy specimens were taken posteriorly at 6-10 cm from 15 patients (four males and 11 females) with classical rheumatoid arthritis (RA) according to the American Rheumatism Association (ARA) criteria (Table 1). There were no complications after this procedure. All had been admitted to hospital for investigation and treatment of their disease. The biopsy specimens were taken as part of an investigation into possible vasculitis and amyloidosis in 11 patients with no gastrointestinal symptoms and from four patients when sigmoidoscopy was performed as part of an investigation into change in bowel habit. Control rectal tissue was taken from patients undergoing investigation for irritable bowel syndrome. Tissue was removed from areas appearing macroscopically normal by the same biopsy technique as for the RA patients.

PREPARATION OF SAMPLES

Rectal biopsy specimens were fixed for electron microscopy in $2.5 \%$ glutaraldehyde in cacodylate 
Table 1 Patient details*

\begin{tabular}{lllllr}
\hline $\begin{array}{l}\text { Patient } \\
\text { No }\end{array}$ & Age & Sex & $\begin{array}{l}\text { Disease } \\
\text { duration } \\
\text { (years) }\end{array}$ & $\begin{array}{l}\text { Extra-articular } \\
\text { manifestations }\end{array}$ & $\begin{array}{l}\text { Reciprocal } \\
\text { latex } \\
\text { titre }\end{array}$ \\
\hline 1 & 35 & M & 10 & 3 & 512 \\
2 & 35 & F & 4 & 4 & Neg. \\
3 & 75 & F & 7 & 2 & 256 \\
4 & 60 & F & 23 & 6 & 1024 \\
5 & 52 & M & 20 & 2 & 256 \\
6 & 51 & M & 17 & 1 & 128 \\
7 & 64 & F & 20 & 5 & 512 \\
8 & 59 & F & 5 & 2 & 256 \\
9 & 59 & M & 6 & 1 & 256 \\
10 & 65 & F & 24 & 4 & 128 \\
11 & 64 & F & 25 & 0 & 128 \\
12 & 69 & F & 14 & 5 & 512 \\
13 & 72 & F & 50 & 4 & 1024 \\
14 & 73 & F & 6 & 1 & 128 \\
15 & 55 & F & 18 & 2 & \\
\hline
\end{tabular}

*All patients had erosion on $x$-ray.

All patients had classical RA by ARA criteria.

buffer $\mathrm{pH} 7.4$ at $4^{\circ} \mathrm{C}$ as soon as possible after the removal of the tissue. Specimens were fixed in $2 \%$ osmium tetroxide, dehydrated in graded ethanols, and embedded in Spurr's resin. ${ }^{9}$ Ultrathin sections were cut with a Reichert OMU2 ultramicrotome, mounted on copper grids, and stained with uranyl acetate and lead citrate. ${ }^{10}$

Sections were viewed in a Siemens Elmiskop 102 electron microscope at an accelerating voltage of 80 $\mathrm{kV}$.

\section{Results}

Macroscopic examination in all patients showed a normal looking rectal mucosa. The cause of the bowel symptoms in the four rheumatoid patients was found to be haemorrhoids in three cases and drug induced diarrhoea in one. Light microscopic examination of the biopsy tissue showed no evidence of either amyloidosis or vasculitis in any of the cases studied. One rheumatoid patient, however, was found to have mild melanosis coli.

In contrast, marked abnormalities were found at the ultrastructural level in the rheumatoid tissue when compared with the control material. The distribution of these abnormalities is shown in Tables 2 and 3 .

RHEUMATOID RECTAL MUCOSA

Ultrastructural changes in the rheumatoid tissue may be categorised as follows.

Siderosomes (Fig. 1)

Twelve of the 15 biopsy specimens examined contained siderosomes. These were mainly the electron $\vec{w}$ dense, membrane bound type and were present in macrophages in the lamina. They were both mores numerous and much more electron dense than those found in the control tissue.

Nearly all of the patients had previously beer? taking oral iron supplement, but patient No 1 whor had the most prominent collections of siderosomes had received no iron.

Expanded endoplasmic reticulum (Figs 1 and 2) In 12 of the 15 biopsy specimens studied endoplas? mic reticulum (ER) (see Table 3) was often presen€ in plasma cells and fibroblasts found just under the basement membrane and scattered throughout lamina. There were no alterations in the endopte혀: mic reticulum of the epithelial cells. The cisternaesto the dilated endoplasmic reticulum were filled with a granular, sometimes fibrillar, electron dense ma을 terial. These 12 biopsy specimens also containeof extracellular ribosome coated vesicles, which we believe are derived from the dilated rough endoplas $\overrightarrow{\vec{B}}$ mic reticulum. These vesicles contain electron dense material similar in appearance to that found in the cisternae of intracellular dilated rough endoplasmie reticulum.

Basement merrbrane (Fig. 3)

A thickened basement membrane was found in foup of the 15 biopsy specimens (see Table 3). The membrane outline was indistinct and surrounded by accumulations of both granular and fibrillar ma terial. Beneath the membrane there were dense

Table 2 Distribution of electron microscopy changes in control tissue

\begin{tabular}{|c|c|c|c|c|c|c|}
\hline $\begin{array}{l}\text { Control } \\
\text { No }\end{array}$ & Siderosomes & $E R^{*}$ & $\begin{array}{l}\text { Mitochondria } \\
+ \text { filaments }\end{array}$ & $\begin{array}{l}\text { Mitochondrial } \\
\text { inclusion }\end{array}$ & $\begin{array}{l}\text { Basement } \\
\text { membranes }\end{array}$ & Complications \\
\hline 1 & + & - & - & - & - & Irritable bowel syndrome \\
\hline 2 & - & + & - & - & - & Irritable bowel syndrome \\
\hline 3 & - & - & - & - & - & Irritable bowel syndrome \\
\hline 4 & + & - & - & - & - & Irritable bowel syndrome \\
\hline
\end{tabular}


Table 3 Distribution of electron microscopy changes

\begin{tabular}{|c|c|c|c|c|c|c|}
\hline $\begin{array}{l}\text { Patient } \\
\text { No }\end{array}$ & Siderosomes & $E R^{+}$ & $\begin{array}{l}\text { Mitochondria } \\
+ \text { filaments }\end{array}$ & $\begin{array}{l}\text { Mitochondrial } \\
\text { inclusion }\end{array}$ & $\begin{array}{l}\text { Basement } \\
\text { membrane }\end{array}$ & Complications \\
\hline 1 & +++ & ++ & ++ & + & - & Fibrosing alveolitis, vasculitis \\
\hline 2 & + & ++ & - & ++ & Thickened & $\begin{array}{l}\text { Acute alveolitis, scleritis, Sjögren`s } \\
\text { syndrome }\end{array}$ \\
\hline 3 & - & ++ & $++t$ & - & - & Leg ulcers \\
\hline 4 & ++ & - & - & - & - & $\begin{array}{l}\text { Deceased, vasculitis, Sjögren's syndrome, } \\
\text { ulcers }\end{array}$ \\
\hline $5^{*}$ & + & ++ & ++ & + & - & Cervical myelopathy, $x$-ray normal \\
\hline $6^{*}$ & + & - & - & + & - & No extra-articular manifestation \\
\hline 7 & ++ & - & - & + & Thickened & $\begin{array}{l}\text { Diabetes mellitis, neuropathic Sjögren's } \\
\text { syndrome and fibrosing alveolitis }\end{array}$ \\
\hline 8 & ++ & + & - & - & Thickened & $\begin{array}{l}\text { Thyrotoxicosis, leg ulcers, Sjögren's } \\
\text { syndrome }\end{array}$ \\
\hline 9 & ++ & + & - & - & - & Felty's syndrome \\
\hline 10 & - & + & ++ & ++ & - & Aortic valve disease. leg ulcers \\
\hline $11^{*}$ & + & ++ & + & + & Thickened & Leg ulcers \\
\hline 12 & + & +++ & - & + & - & $\begin{array}{l}\text { Felty's syndrome, neuropathy, Sjögren's } \\
\text { syndrome }\end{array}$ \\
\hline 13 & + & ++ & + & + & - & Neuropathy, leg ulcers \\
\hline $14^{*}$ & ++ & + & - & ++ & - & Sjögren’s syndrome \\
\hline 15 & - & ++ & - & - & - & Sjögren's syndrome \\
\hline
\end{tabular}

*Investigated for change in bowel habit.

$+E R=$ endoplasmic reticulum.

-None; +few; ++moderate; +++many.

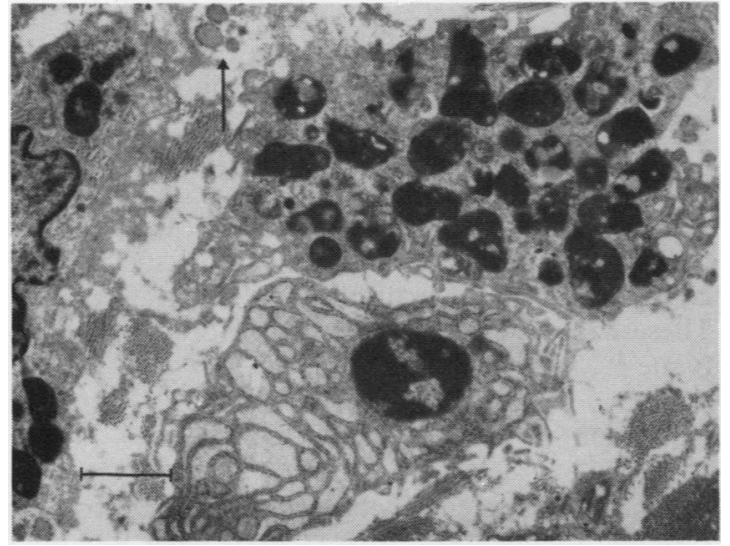

Fig. 1 Electron micrograph from patient No. 8, showing the irregularly shaped electron dense membrane bound siderosomes. In an adjacent cell expanded endoplasmic reticulum containing a granular/fibrillar material can be seen. There are a few small extracellular ribosome coated vesicles (arrow) which may be derived from the dilated endoplasmic reticulum. (Scale line $=2 \mu \mathrm{m}$ ).

patches of fibrils associated with collagen and small lipid inclusions.

Mitochondrial inclusions (Fig. 2)

Electron dense mitochondrial inclusions were mainly found in the columnar cells of the epithelium

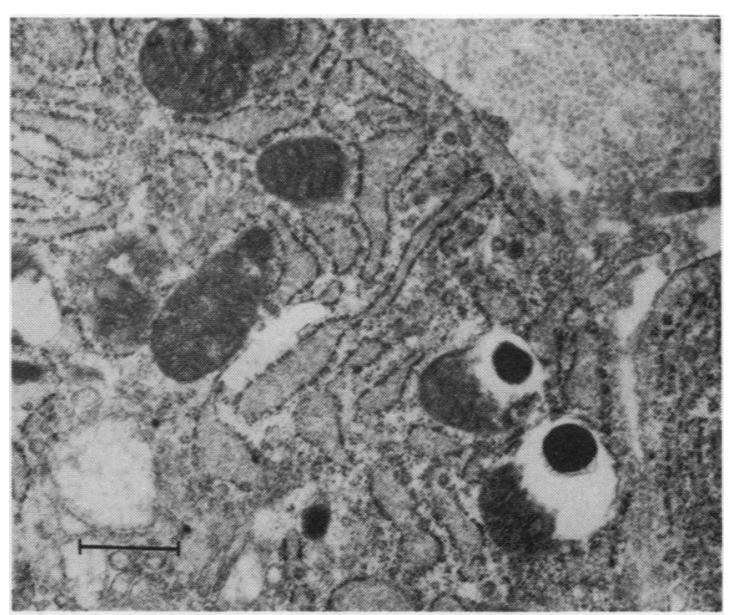

Fig. 2 Electron micrograph from patient No 13. Well preserved mitochondria are positioned adjacent to two mitochondria each of which contains a very electron dense inclusion. The internal structure of these mitochondria has been grossly disrupted. The expanded endoplasmic reticulum is seen here at higher power clearly showing the granular contents. (Scale line $=500 \mathrm{~nm})$.

but were also present in fibroblasts, macrophages, and plasma cells throughout the lamina propria mucosae in 10 of the 15 biopsy specimens examined. Fig. 2 shows two adjacent mitochondria with grossly 


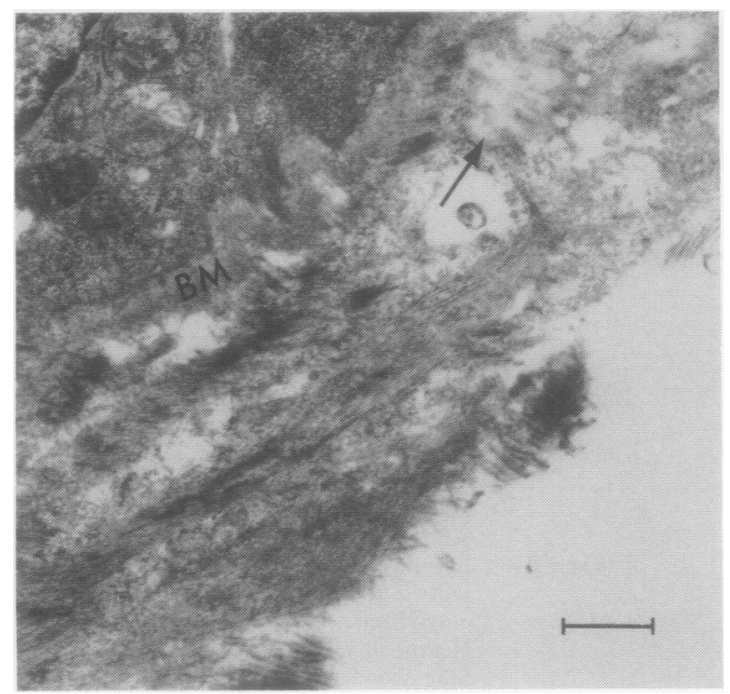

Fig. 3 Electron micrograph from patient No 2 showing the altered basement membrane (BM) with the very prominent accumulations of fibrillary material beneath $i t$. Within the mass of fibrils surrounded by a granular deposit there is a small lipid inclusion (arrow). (Scale line $=500 \mathrm{~nm}$ ).

disrupted internal structure, each containing a very electron dense inclusion. These have been dismissed in the past as fixation artefacts. However, closely positioned to these abnormal mitochondria is a group of perfectly preserved whole mitochondria. These inclusions were found to be in two forms,

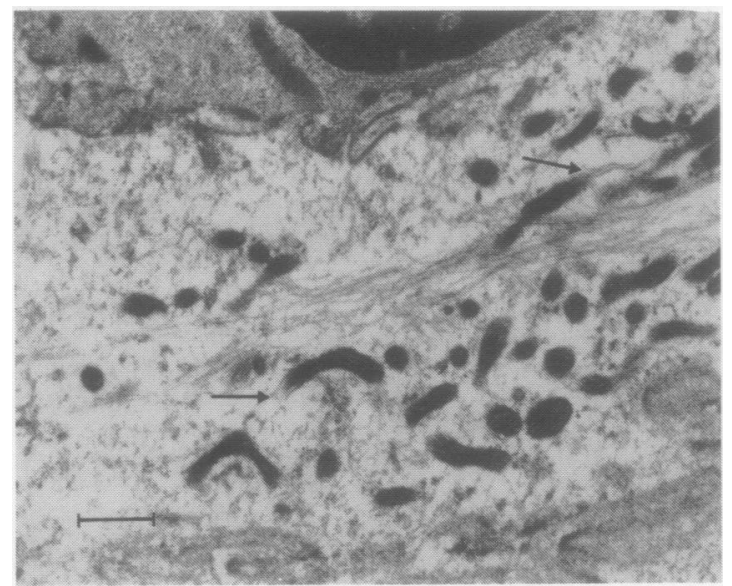

Fig. 4 Electron micrograph from patient No 3. Mitochondria are grouped around bundles of filaments, some of the mitochondria appear to have 'tails' of filaments (arrows). The cell cytoplasm is very sparse and few other organelles are present. $($ Scale line $=500 \mathrm{~nm})$. those shown in Fig. 2 and a different form consisting of whorls of electron dense membranes.

Mitochondria and filaments (Fig. 4)

Mitochondria associated with fine cytoplasmic fila은 ments were found in six of the 15 biopsy specimen examined (see Table 3 ). They were present in cells? in the lamina, usually well below the basemen 8 membrane. These cells contained sparse cytoplasmes with very few organelles present, which madeidentification difficult. They were not a feature of normal rectal tissue. The mitochondria often $\vec{\omega}$ appeared grouped around large bundles of theses fine filaments. Some of the mitochondria appeareç to have 'tails' of fine filaments trailing from one end.

CONTROL RECTAL MUCOSA

The control tissue displayed essentially normak ultrastructure, though minimal changes were found.으

\section{Siderosomes}

ले

Controls 1 and 4 (Table 2) had small collections oP pale siderosomes in a few of the macrophages in the lamina. These were of the electron dense membrane्ष bound form as described by Richter. ${ }^{11}$

\section{Expanded endoplasmic reticulum}

Control 2 had a few collections of ribosome coa esp vesicles in the extracellular matrix of the laminas These vesicles contained a granular/fibrillar electron opaque material.

No other alterations were found, though many of the mitochondria throughout the tissue of the controls displayed small electron dense inclusions 3 These are often seen in mitochondria in healthy tissue. $^{12}$

\section{Discussion}

Clinical involvement of the gastrointestinal tract it systemic rheumatoid disease, apart from Sjögren'옹 syndrome, is uncommon. ${ }^{13}$ Certainly both amyloidosis $^{14}$ and rheumatoid vasculitis ${ }^{15-17}$ have been reported, but amyloid accumulation has to bes massive before gastrointestinal malfunction occurs? and vasculitic catastrophes are only the subject of case reports. Histological evidence of systemic involvement is more common, and the rectal biopsp has to be accepted as providing a high rate ow diagnosis in both conditions. ${ }^{18} 19$ Certainly the findings of Cruickshank ${ }^{20}$ in a postmortem stude would suggest that histological vasculitis is mucto more common and widespread than had beent previously thought.

The presence of iron in rheumatoid tissue is subject that has been widely investigated. ${ }^{21-23} \mathrm{~W}$ 
know that siderosomes are associated with iron deposition, ${ }^{11}$ and in the human synovium they are found in the macrophage like type $A$ cells. ${ }^{22}$ In rheumatoid synovial tissue links have been made between the duration of the inflammatory process and the degree of iron deposition. ${ }^{24}$ Muirden $^{25}$ showed the presence of large quantities of ferritin in the cells of the rheumatoid synovium. One explanation offered for this is that iron may be diverted from the plasma and deposited in the inflamed synovial tissue. In the rheumatoid rectal tissue we were unable to link the presence of siderosomes with oral iron overload, suggesting that the iron accumulation may be related to the chronic disease process. Several authors have suggested ${ }^{26} 27$ that iron has a vital role in the disease process, with intracellular damage being caused by free radical production.

Siderosomes and mitochondrial inclusions are found in two forms, whorls of electron dense membranes and amorphous electron opaque bodies. Ghadially and Roy ${ }^{28}$ noted encapsulated membranous whorls in synovial cells and concluded that they were cytolysosomes. The action of lysosomal enzymes has been proposed as a mechanism of damage in the synovium and has been widely investigated. ${ }^{29}$

32 We did not find the membranous form of siderosome or mitochondrial inclusion in the control tissue. There were, however, small collections of pale siderosomes in some macrophages in the lamina and very small electron dense inclusions in the mitochondria of the normal tissue. There is evidence to suggest that the small mitochondrial inclusions bind divalent cations within the mitochondria to regulate the internal ionic concentration. ${ }^{33}$ This results in the small inclusions becoming more prominent. The size of the inclusions does not increase, but they become more electron dense. The internal structure of the mitochondria remains undisturbed. In the rheumatoid tissue the mitochondrial inclusions are usually surrounded by an electron lucent area. The inclusions can be so large that they replace the internal structure of the mitochondria.

The presence of fine filaments both intracellularly in association with the mitochondria and extracellularly in association with the basement membrane is particularly interesting. We have previously noted the association between mitochondria and cytoplasmic filaments in rheumatoid synovium ${ }^{34}$ and are currently investigating the presence of extracellular filaments with relation to the diagnosis of amyloid (unpublished data). Other authors have evidence to suggest associations between mitochondria and intracellular filaments. Toh and Lolait ${ }^{35}$ have shown that when monolayers of cultured fibroblasts are treated with colchicine the cytoplasmic filaments and the mitochondria are relocated into perinuclear coils. This suggests a functional association between the mitochondria and the cytoplasmic filaments.

The presence of altered endoplasmic reticulum in the rheumatoid rectal tissue also parallels our observations in the rheumatoid synovial tissue. ${ }^{34} 36$ In both tissues dilated endoplasmic reticulum is present intracellularly and extracellularly as ribosome coated vesicles. Both contain a granular or fibrillar electron dense material. As a result of our studies of synovial tissue from a wide range of rheumatoid arthropathies we came to the conclusion that the presence of the altered endoplasmic reticulum was indicative of a general inflammatory response and was not linked to any particular disease process.

In rheumatoid rectal mucosa prominence of siderosomes, expanded endoplasmic reticulum, and mitochondrial inclusions appear to be the most noticeable findings. There appears to be no correlation between either age, sex, or duration of disease and the presence of abnormal features. It is possible that these findings indicate generalised intracellular changes in patients with rheumatoid arthritis. Biopsy specimens from other sites would be needed to confirm this. In such a highly selected group of patients with longstanding and severe disease it may just be indicative of cellular degeneration as a result of the chronic inflammatory process. It is interesting that these two sites, synovium and rectum, should show similar changes, since synovitis (the active joint process) and vasculitis/amyloidosis (indicative of extra-articular disease) are considered by some authors to be almost mutually exclusive in their active phase. ${ }^{37}$

These findings of marked ultrastructural changes in the rectal mucosa of patients with severe and longstanding rheumatoid arthritis have raised important questions about the pathogenesis of the disease. How these changes are caused is not discernible from the morphology alone. All of these patients have at some time during treatment used suppository preparations of non-steroidal antiinflammatory drugs. Perhaps these have influenced the development of some of our findings in the rectal tissue. The results of our investigations indicate several areas for further fruitful enquiry.

C A Hollywell and $\mathrm{C} \mathbf{J}$ Morris are supported by the Arthritis and Rheumatism Council for Research. Thanks to Dr H Bradby and Dr E Elias for supplying the control tissue.

\section{References \\ 1 Williams R C Jr. Rheumatoid arthritis as a systemic disease. Philadelphia: Saunders, 1974.}


2 Watson Buchanan W. Clinical features of rheumatoid arthritis. In: Scott J T, ed. Copeman textbook of the rheumatic diseases. 5th ed. Edinburgh: Churchill Livingstone, 1978: 318-65.

3 Bywaters E G L, Scott J T. The natural history of vascular lesions in rheumatoid arthritis. J Chronic Dis 1963; 16: 905-14.

4 Ramos M, Mandybur T I. Cerebral vasculitis in rheumatoid arthritis. Arch Neurol 1975; 32: 271-5.

5 Pallis C A, Scott J T. Peripheral neuropathy in rheumatoid arthritis. Br Med J 1965; i: 1141-7.

6 Scott D G I, Bacon P A, Tribe C R. Systemic rheumatoid vasculitis, a clinical and laboratory study of 50 cases. Medicine (Baltimore) 1981; 60: 288-97.

7 Doblough J H, Fore O, Kass E, Thorsby E. HLA antigens and rheumatoid arthritis association between HLA-DRw4 positivity and IgM rheumatoid factor production. Arthritis Rheum 1980; 23: 309-13.

8 Panayi G S, Wooley P, Bachelor J R. Genetic basis of rheumatoid disease HLA antigens, disease manifestations and toxic reactions to drugs. $\mathrm{Br}$ Med J 1978; ii: 1325-8.

9 Spurr A R. A low viscosity epoxy resin embedding medium for electron microscopy. J Ultrastruct Res 1969; 26: 31-43.

10 Reynolds E S. The use of lead citrate at high $\mathrm{pH}$ as an electron opaque stain in electron microscopy. J Cell Biol 1963; 17: 208-12.

11 Richter G W. A study of haemosiderosis with the aid of electron microscopy. J Exp Med 1957; 106: 203-18.

12 Rhodin J A G. An atlas of ultrastructure. Philadelphia and London: Saunders, 1963.

13 Hawkins C F. Rheumatic diseases and the alimentary tract Practitioner 1978; 220: 59-68.

14 Missen G A K, Tailor J D. Amyloidosis in rheumatoid arthritis. J Pathol 1956; 71: 179-92.

15 Parker R A, Thomas P M. Intestinal perforation and widespread arteritis in rheumatoid arthritis during treatment with cortisone. $\mathrm{Br}$ Med J 1959; i: 540-2.

16 Schneider R E, Dobbins W O. Suction biopsy of the rectal mucosa for diagnosis of arteritis in rheumatoid arthritis and related diseases. Ann Intern Med 1968; 68: 561-8.

17 Lindsay M K, Tavadia H B, Whyte A S, Lee P, Webb J. Acute abdomen in rheumatoid arthritis due to necrotising arteritis. $\mathrm{Br}$ Med J 1973; ii: 592-3.

18 Arapakis G, Tribe C R. Amyloidosis in rheumatoid arthritis investigated by means of rectal biopsy. Ann Rheum Dis 1963; 22: $256-62$.

19 Tribe C R, Scott D G I, Bacon P A. Rectal biopsy in the diagnosis of systemic vasculitis. J Clin Pathol 1981; 34: 843-50.

20 Cruickshank B. The arteritis of rheumatoid arthritis. Ann Rheum Dis 1954; 13: 136-46.
21 Lawson A A H, Owen E T, Mowat A G. Nature of anaemia in rheumatoid arthritis. VII. Storage of iron in rheumatoig disease. Ann Rheum Dis 1967; 26: 552-9.

22 Muirden K D. The anaemia of rheumatoid arthritis and the significance of deposits in the synovial membrane. Aust Ann Med 1970; 2: 97-104.

23 Ogilvie-Harris D J, Fornaiser V L. Synovial iron deposition in osteoarthritis and rheumatoid arthritis. J Rheumatol 1980; 7 $\bar{n}$. 30-6.

24 Kumar R, Garg W L. Hemosiderin iron in synovial tissue in rheumatoid and tubecular arthritis a reassessment of the mechanism of deposition. Indian J Med Res 1974; 62: 1146-51.

25 Muirden K D. Ferritin in synovial cells in patients with rheumatoid arthritis. Ann Rheum Dis 1966; 25: 387-401.

26 Blake D R, Hall N D, Bacon P A, Dieppe P A, Halliwell B $\vec{\omega}$ Gutteridge J M C. The importance of iron in a rheumatoid disease. Lancet 1981; ii: 1142-4.

27 Wickens D G, Dormandy T L. Further studies of fluorescence free radical products in synovial fluid. Clin Rheumatol 1982; 1 i $151-2$.

28 Ghadially F N, Roy S. Ultrastructure of synovial membrane ing rheumatoid arthritis. Ann Rheum Dis 1967; 26: 426-43.

29 Smith C, Hamerman D. Acid phosphatase in human synoviab fluid. Arthritis Rheum 1962; 5: 411-4.

30 Luscombe $M$. Acid phosphatase and catheptic activity in rheumatoid synovial tissue. Nature 1963; 197: 1010.

31 Beckman G, Beckman L, Lemperg R. Acid phosphatas $\frac{\mathbb{D}}{\mathscr{D}}$ activity in the synovial fluid of patients with rheumatoid arthritis and other joint disorders. Acta Rheumatol Scand 1971; 1: 47-56

32 Muirden K D. Lyososomal enzymes in synovial membrane in rheumatoid arthritis. Ann Rheum Dis 1972; 31: 265-71.

33 Peachey L D. Electron microscopic observations on fife accumulation of divalent cations in intramitochondrial granu+ss J Cell Biol 1964; 20: 95-111.

34 Morris C J, Hollywell C A, Scott D L, Farr M, Hawkins CFO Walton K W. Ultrastructure of the synovial membrane in seronegative inflammatory arthropathies. J R Soc Med 1983; 76б 27-31.

35 Toh B H, Lolait S J, Mathy J P, Baum R. Association of mitochondria with intermediate filaments and polyribosomes with cytoplasmic actin. Cell Tissue Res 1980; 211: 163-9.

36 Hollywell C A, Morris C J, Farr M, Walton K W. Ultrastruc ture of synovial changes in rheumatoid disease and in seronega? tive inflammatory arthropathies. Virchows Arch [Pathol Anatp 1983; 400: 345-55.

37 Anonymous. Lepromatous rheumatoid [Editorial]. Lances 1982; ï: 748-9. 